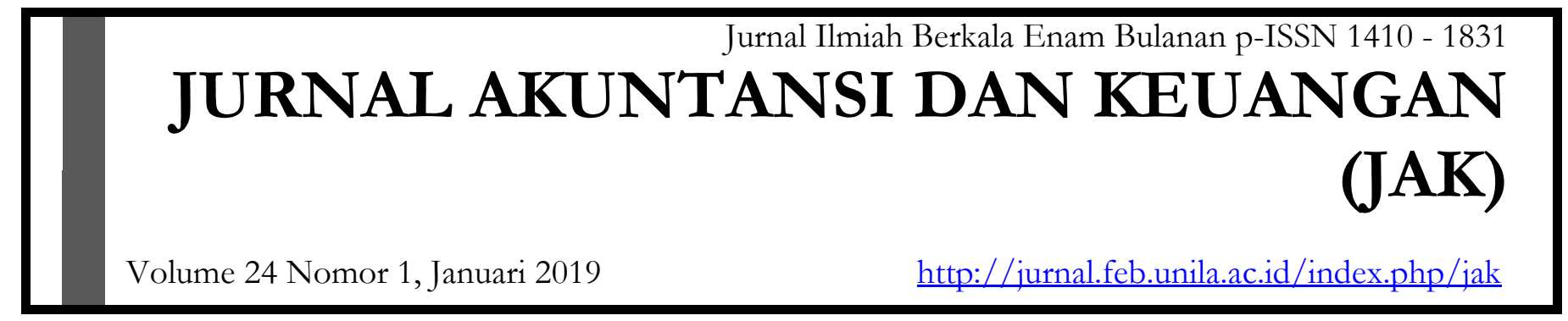

\title{
EARNINGS MANAGEMENT PADA TITIK KRITIS PERUBAHAN TAHAP LIFE CYCLE: STUDI EMPIRIS PADA PERUSAHAAN MANUFAKTUR DI INDONESIA
}

\author{
Baharudin Ludfi Syuhada ${ }^{1}$, Susi Sarumpaet ${ }^{2}$ \\ 1 Jurusan Akuntansi Fakultas Ekonomi dan Bisnis Universitas Lampung \\ 2 Jurusan Akuntansi Fakultas Ekonomi dan Bisnis Universitas Lampung
}

\section{Informasi Naskah}

\section{Update Naskah:}

Dikumpulkan:18 September 2018

Diterima: 19 Desember 2018

Terbit/Dicetak: 29 Januari 2019

\section{Keywords:}

corporate life cycle, discretionary accruals, earnings management, manufacturing companies, Indonesia.

\section{$\underline{\text { Abstract }}$}

Corporations pass every stage of their life cycles through different ways. At each point of these stages a company has the possibility to turn into decline. When this occurs, a company has the incentive to manage earnings in order to maintain its performance reflected in reported earnings. The objective of this study is to examine whether earnings management choices are different in corporate life cycles from growth to mature and mature to stagnant.

The differences in earning management behaviour were indicated by negative and positive discretionary accruals. The sample was taken from manufacturing firms listed on the Indonesia Stock Exchange (2006 to 2013) in different life stages. The results show that firms in growth-mature and mature-stagnant did manage earnings through discretionary accruals, as indicated by significant differences as compared to those in other corporate life cycles. 


\section{A. PENDAHULUAN}

Bahan Bakar Minyak merupakan salah satu komiditi yang sangat berpengaruh terhadap perekonomian di Indonesia.Sebagaimana yang kita ketahui, saat ini Indonesia sedang mengalami masalah naiknya harga Bahan Bakar Minyak. Hal ini dikarenakan permintaan masyarakat terhadap Bahan Bakar Minyak yang membubung tinggi sementara penyediaannya mengalami kekurangan yang membuat harga barang tersebut menjadi naik dan timbulnya inflasi. Kenaikan harga Bahan Bakar Minyak memperberat beban hidup masyarakat terutama mereka yang berada di kalangan bawah dan juga para pengusaha, karena kenaikan Bahan Bakar Minyak menyebabkan turunnya daya beli masyarakat dan itu akan mengakibatkan tidak terserapnya semua hasil produksi banyak perusahaan sehingga akan menurunkan tingkat penjualan yang pada akhirnya juga akan menurunkan laba perusahaan (The President Post,2013). Kenaikan Bahan Bakar Minyak yang menurunkan laba ini berpengaruh juga terhadap siklus hidup perusahaan di Indonesia. Setiap perusahaan memiliki siklus hidup yang berbeda-beda. Tidak semua perusahaan mengalami siklus hidup yang sempurna, adakalanya perusahaan hanya mencapai pada titik kritis pertumbuhan atau kedewasaan namun kemudian mengalami kemunduran. Bahkan, beberapa perusahaan yang baru mencapai tahap perkenalan juga dapat mengalami kemunduran tanpa mengalami tahap pertumbuhan. Dalam hal ini perlu adanya tindakan manajemen untuk mengambil langkah-langkah perbaikan dan melakukan penataan ulang untuk mengatasi permasalahan khususnya pada titik kritis perubahan siklus hidup perusahaan.

Perusahaan memiliki life cycle (siklus hidup) seperti halnya dengan produk (Schori dan Garee 1998). Terdapat empat tahap siklus hidup perusahaan, yaitu tahap introduction, growth, maturity, dan decline. Ada beberapa penelitian yang menghubungkan laba dengan siklus hidup perusahaan. Contohnya adalah Anthony dan Ramesh (1992) yang meneliti hubungan antara ukuran kinerja akuntansi dan harga saham dengan menggunakan uji hipotesis siklus hidup dengan membagi siklus hidup ke dalam tiga tahap yaitu growth, mature, dan stagnant. Black (1998) membandingkan relevansi nilai laba dan arus kas dalam setiap tahap siklus hidup dengan menggunakan metodologi Anthony dan Ramesh (1992). Hastuti (2006) meneliti tentang perbedaan perilaku manajemen laba berdasarkan pada perbedaan siklus hidup perusahaan. Kemudian, Hastuti (2010) meneliti perbedaan manajemen laba dilihat dari pemilihan kebijakan akuntansinya yang menaikkan laba atau menurunkan laba. Namun, kedua penelitian terakhir hanya melihat perbedaan perilaku manajemen laba dari akrualnya saja terhadap perusahaan yang berada pada tahap growth, mature, dan stagnant dan tidak melihat bagaimana pada saat terjadi perubahan siklus hidup perusahaan. Penulis ingin meneliti apakah ada perbedaan antara manajemen laba yang terjadi pada saat titik kritis perubahan siklus hidup perusahaan dengan yang tidak terjadi.

\section{B. LANDASAN TEORI DAN PENGEMBANGAN HIPOTESIS}

\section{Agency Theory}

Perikatan antara dua orang atau lebih memunculkan hubungan keagenan. Pihak yang ditunjuk disebut agen. Agen bertugas mengambil keputusan dan mewakili kepentingan pihak yang menunjuk yang disebut para prinsipal (principals) dengan pihak lain yang secara umum berhubungan dengan pemecahan suatu masalah. Agar agen dapat mengerjakan tugas-tugasnya, prinsipal mendelegasikan wewenang pengambilan keputusan sampai batas tertentu kepada agen. Hubungan keagenan merupakan salah satu 
bentuk hubungan yang tertua dan umumnya merupakan ciri dari interaksi sosial (Ross,1973). Masalah utama yang muncul dalam hubungan ini adalah agen akan mengutamakan kepentingannya dan memilih perilaku yang menghasilkan kesejahteraan tertinggi baginya (Jensen dan Meckling, 1976).

\section{Manajemen Laba Akrual}

Istilah earnings management atau manajemen laba merupakan istilah yang sudah biasa didengar, baik oleh praktisi maupun akademisi dari akuntansi dan manajemen. Terdapat beberapa istilah umum yang sering digunakan oleh para praktisi dan kalangan bisnis mengenai manajemen laba, antara lain creative accounting practices, income smoothing, income manipulation, agressive accounting, financial number game, dan masih banyak istilah lainnya yang dapat digunakan secara bergantian yang kadarnya mulai dari tingkatan sopan sampai pada tingkatan kotor dan membahayakan publik.

Manajemen laba akrual ditunjukkan dengan adanya discretionary accrual. Penelitian yang menganalisis manajemen laba dengan melihat adanya discretionary accrual adalah Hayn (1995) yang menyatakan bahwa manajemen laba dapat dilakukan oleh manajemen pada saat perusahaan tersebut masih bertumbuh, bahkan dilakukan juga pada saat laba perusahaan jatuh mendekati poin nol. Degeorge et al. (1999) menyatakan bahwa perusahaan yang growth melaporkan laba yang meningkat untuk mencapai ramalan laba para analis. Dengan berbagai cara, para manajer mempengaruhi peramalan analis untuk mengelola laba agar tepat dengan peramalan.

\section{Siklus Hidup (Life Cylce) Perusahaan}

Masing-masing produk terdiri dari sekumpulan merk, yang setiap merknya memiliki brand life cycle. Jika suatu perusahaan hanya terfokus pada satu brand life cycle, perusahaan akan kehilangan gambaran yang lebih besar mengenai apa yang terjadi dengan life cycle produk. Jadi, perusahaan tidak hanya memberikan perhatian terhadap suatu merk produk, tetapi harus memperhatikan teknologi yang baru yang akan merusak pasar produk tertentu

Pada tahap growth, perusahaan digambarkan seperti anak remaja yang belum dewasa. Pada tahap ini, perusahaan mulai memenuhi kebutuhan pasar dan pertumbuhannya cepat. Pertumbuhan ini merupakan hasil dari pemenuhan kebutuhan pasar yang lebih baik daripada kompetisi dan semangat usaha dari pendiri perusahaan tersebut.Pada tahap mature, perusahaan digambarkan seperti orang dewasa. Perusahaan memasuki tahap dimana para manajernya mulai profesional. Tetapi umur perusahaan tidak panjang lagi dan mengarah pada tahap akhir dalam life cycle perusahaan. Ada beberapa perusahaan yang tetap berada pada tahap ini untuk jangka waktu yang panjang tapi ada juga yang mengarah pada kebangkrutan. Tahap terakhir dari life cycle perusahaan adalah decline. Pada tahap ini, perusahaan digambarkan sebagai orang yang lanjut usia. Perusahaan mengalami penurunan, penurunan, dan penurunan. Perusahaan akan menghentikan kegiatannya. Perusahaan akan meninggalkan bisnisnya. Seluruh harapan dan mimpi yang berkaitan dengan perusahaan akan hilang.

Pada tahap setelah mature, ada perusahaan yang tidak memasuki tahap decline tetapi tetap berada pada posisi yang stabil (stagnant). Perusahaan tidak begitu mengalami peningkatan penjualan dan penurunan laba yang cukup drastis. Tingkat pertumbuhan penjualan rendah, perusahaan tidak melakukan pengeluaran modal besar-besaran, dan laba yang diperoleh perusahaan tidak lagi banyak ditahan untuk pengembangan perusahaan (Anthony dan Ramesh 1992). 


\section{Hubungan antara Manajemen Laba dan Siklus Hidup Perusahaan}

Manajemen laba dapat dilakukan oleh manajemen pada saat perusahaan tersebut masih bertumbuh, bahkan dilakukan juga pada saat laba perusahaan jatuh mendekati poin nol (Hayn 1995). Pada saat perusahaan bertumbuh (growth), perusahaan mulai menghasilkan laba. Perusahaan mulai melakukan diversifikasi dalam lini produk yang berhubungan erat. Biasanya perusahaan yang berada pada tahap bertumbuh, struktur pengelolaannya masih lemah.

Shank dan Govindarajan (1993) mengemukakan bahwa perusahaan yang berada pada tahap perkenalan dan pertumbuhan menerapkan sistem pengendalian yang tidak ketat, tetapi bila sudah mencapai pada fase kematangan atau harvest (dalam hal ini dikategorikan ke dalam tahap mature) dan penurunan maka akan menerapkan sistem pengendalian yang ketat. Semakin ketat sistem pengendalian, diharapkan manajemen laba yang dilakukan semakin rendah. Hastuti (2006) menunjukkan bahwa manajemen laba perusahaan yang berada pada tahap stagnant lebih rendah secara signifikan daripada perusahaan yang berada pada tahap mature.

Menurut Peasnell et al. (2005), manajer lebih memilih menaikkan laba untuk menghindari pelaporan rugi dan laba yang menurun. Dengan demikian, dapat diduga perusahaan pada titik kritis growth-mature dan mature-stagnant cenderung melakukan pemilihan kebijakan akuntansi menaikkan laba. Berdasarkan ekspektasi yang diuraikan tersebut, dirumuskan hipotesis alternatif sebagai berikut:

H1: Perusahaan yang berada pada tahap growth-mature memiliki perbedaan yang signifikan dengan yang tidak berada pada titik kritis perubahan siklus hidup perusahaan.

H2: Perusahaan yang berada pada tahap mature-stagnant memiliki perbedaan yang signifikan dengan yang tidak berada pada titik kritis perubahan siklus hidup perusahaan.

\section{METODE PENELITIAN}

\section{Populasi dan Sampel dan Sumber Data}

Populasi yang digunakan dalam penelitian ini adalah seluruh perusahaan manufaktur yang terdaftar di Bursa Efek Indonesia dengan beberapa alasan sebagai berikut: (a) untuk menghindari perbedaan karakteristik antara perusahaan manufaktur dan non-manufaktur. (b) capital expenditure, yaitu pengeluaran investasi dalam bentuk plant, property, and equipment, digunakan sebagai salah satu variabel klasifikasi untuk menentukan tahap life cycle perusahaan. Adapun karakteristik pemilihan sampel yang digunakan untuk penelitian ini adalah sebagai berikut: (a) perusahaan publik yang terdaftardi Bursa Efek Indonesia (BEI), (b) periode penelitian adalah tahun 2007-2013, (c) perusahaan yang mempublikasikan laporan keuangan tahunan secara konsisten dari tahun 2006 sampai dengan 2013. Karena data discretionary accruals membutuhkan data tahun sebelumnya, maka data tahun 2006 dibutuhkan untuk memperoleh data satu tahun sebelum tahun 2007.

Data yang digunakan dalam penelitian ini dikumpulkan dari laporan keuangan perusahaan Manufaktur periode 2006-2013 yang diperoleh dari Bursa Efek Indonesia dan Indonesian Capital Market Directory (ICMD). Pengumpulan data dilakukan dengan menggunakan data dokumentasi yaitu data sekunder yang berupa annual report yang go public dan yang dipublikasikan. 


\section{Defenisi dan Pengukuran Variabel}

Penelitian ini mengklasifikasikan lifecycle perusahaan ke dalam tiga tahap, yaitu growth, mature, dan stagnant. Tahap start-up tidak diteliti karena tidak dapat memenuhi kriteria perusahaan yang berada pada tahap start-up yaitu perusahaan mulai melakukan penjualan tidak lebih dari satu tahun sebelum gopublic.Hal ini disebabkan karena BEI mensyaratkan perusahaan harus sudah mendapatkan laba bersih dan laba operasi selama dua tahun fiskal terakhir agar saham perusahaan dapat dicatatkan di bursa. Penelitian yang telah membuktikan hal tersebut adalah penelitian Atmini (2002).

Pengklasifikasian ke dalam tiga tahap dilakukan berdasarkan penelitian Anthony dan Ramesh (1992). Ada empat variabel klasifikasi: (1) pembayaran dividen per tahun sebagai persentase dari laba (DP), (2) persentase pertumbuhan penjualan (SG), (3) capitalexpenditure sebagai persentase total nilai perusahaan (CEV), dan (4) umur perusahaan (AGE). Tabel 1 menyajikan ekspektasi keempat variabel tersebut berdasarkan Anthony dan Ramesh (1992)

Masing-masing variabel tersebut dihitung dengan cara berikut:

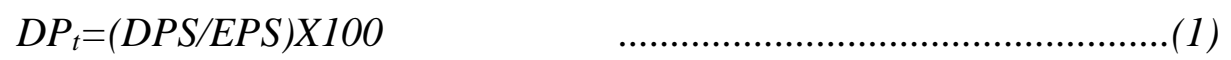

$$
\begin{aligned}
& S G_{t}=\left(\left(S A L E S_{t}-S A L E S_{t-1}\right) / S A L E S_{t-1}\right) X 100
\end{aligned}
$$

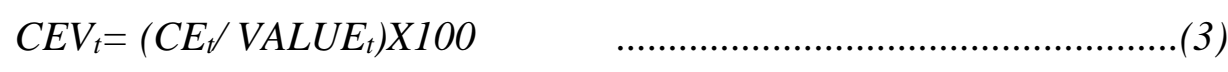

$$
\begin{aligned}
& A G E=\text { tahun berjalan }- \text { tahun terbentuknya perusahaan ......................(4) }
\end{aligned}
$$

\section{Keterangan:}

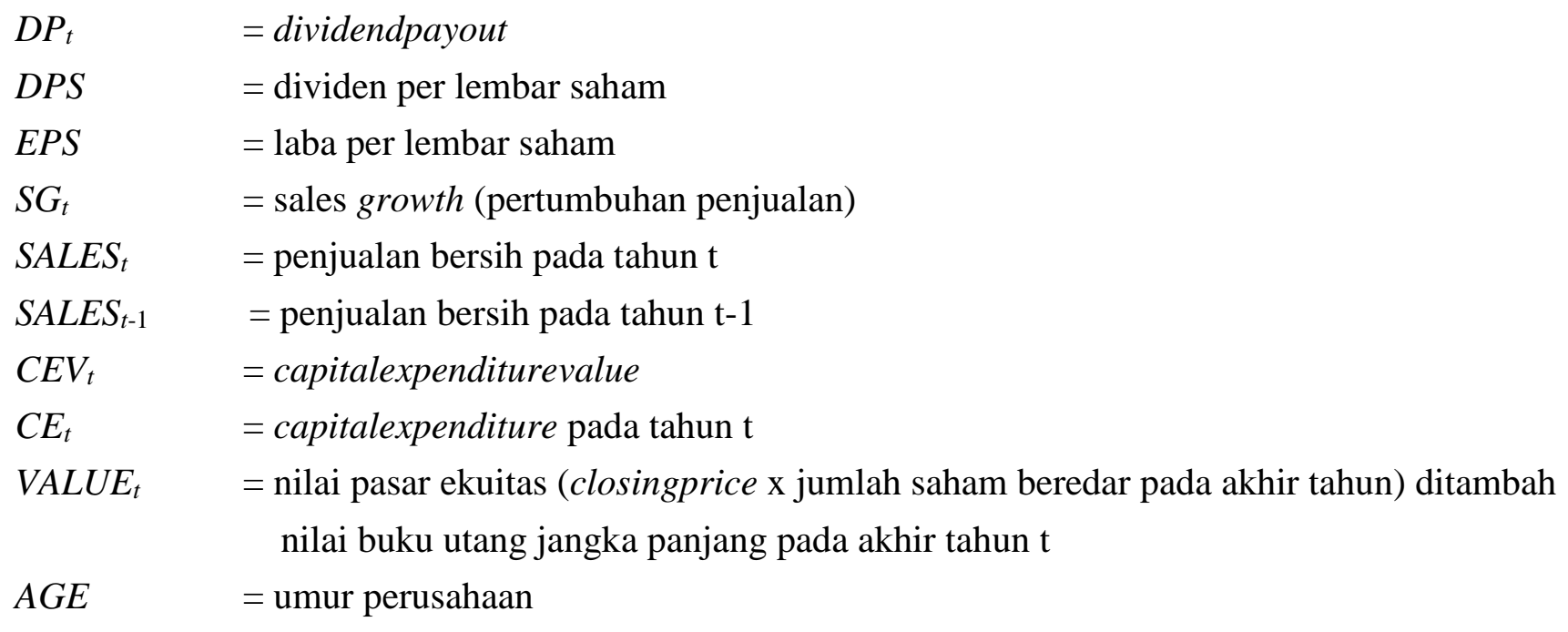

Setelah itu, skor peringkat variabel klasifikasi dan skor peringkat gabungan dibagi ke dalam kuintil (quintile). Keempat variabel diatas di analisa dengan analisis faktor, dibagi menjadi empat bagian selama delapan tahun. Kuartil terendah merupakan perusahaan dalam tahap decline, kuartil tertinggi merupakan tahap growth dan kuartil tengah merupakan tahap maturebegitupula sebaliknya sesuai dengan kriteria siklus hidup perusahaan.

Perhitungan kuartil ditentukan dengan rumussebagai berikut:

Letak $(Q i)=$ data ke $\frac{i(n+1)}{4}$ 
Keterangan:

Qi = kuartil ke-i

$n \quad=$ Banyaknya data

$i \quad=1,2,3$

Perusahaan diklasifikasikan ke dalam tahap growth, mature, dan stagnant dengan kriteria sebagai berikut:

1. Growth: apabila suatu tahun-perusahaan berada pada kuintil tertinggi gabungan skor peringkat pertumbuhan penjualan dan capitalexpenditure dan berada pada kuintil terendah gabungan skor peringkat dividendpayout dan umur perusahaan.

2. Mature: apabila suatu tahun-perusahaan berada pada kuintil tengah gabungan skor peringkat pertumbuhan penjualan dan capitalexpenditure, berada pada kuintil tengah skor peringkat dividendpayout, dan berada pada kuintil tengah skor peringkat umur perusahaan.

3. Stagnant: apabila suatu tahun-perusahaan berada pada kuintil terendah gabungan skor peringkat pertumbuhan penjualan dan capitalexpenditure, berada pada kuintil tertinggi skor peringkat dividendpayout, dan berada pada kuintil tertinggi skor peringkat umur perusahaan.

Penggunaan discretionary accruals sebagai proksi manajemen laba dihitung dengan menggunakan model Jones yang dimodifikasi (Dechow et al. 1995). Discretionary accrual diperoleh dengan terlebih dahulu mengukur total accrual. Total accrual (TAC) dihitung dengan rumus berikut:

$$
T A C_{t}=N I_{t}-C F O_{t}
$$

Keterangan:

$\mathrm{TAC}_{\mathrm{t}}=$ total accrual pada tahun $\mathrm{t}$

$\mathrm{NI}_{\mathrm{t}} \quad=$ laba bersih pada tahun $\mathrm{t}$

$\mathrm{CFO}_{\mathrm{t}}=$ arus kas operasi perusahaan i pada tahun $\mathrm{t}$

Nilai akrual yang diperoleh dari persamaan di atas dideflasi dengan nilai total aset (Chan et al. 2001).

Selanjutnya dilakukan dekomposisi komponen total accrual ke dalam komponen discretionary accrual dengan non discretionary accrual. Dekomposisi ini dilakukan dengan mengacu pada model Jones yang dimodifikasi (Dechow et al. 1995) berikut ini:

Nilai non discretionary accrual (NDAC) dihitung dengan formula berikut:

$$
N D A C=a_{1}\left[1 / T A_{t-1}\right]+a_{2}\left[\Delta R E V_{t}-\Delta R E C_{t} / T A_{t-1}\right]+a_{3}\left[P P E_{t} / T A_{t-1}\right]
$$

Nilai a1, a2, dan a3 pada persamaan di atas diperoleh dari persamaan regresi OLS berikut:

$$
T A C_{t} / T A_{t-1}=a_{1}\left[1 / T A_{t-1}\right]+a_{2}\left[\Delta R E V_{t} / T A_{t-1}\right]+a_{3}\left[P P E_{t} / T A_{t-1}\right]+\varepsilon_{t}
$$

Untuk menghitung nilai discretionary accrual (DAC) yang merupakan ukuran manajemen laba, diperoleh dari formula berikut:

$$
D A C_{t}=T A C_{t} / T A_{t-1}-N D A C
$$


Keterangan:

$\mathrm{TAC}_{\mathrm{t}} \quad=$ total accrual pada tahun $\mathrm{t}$

$\mathrm{NDAC}_{\mathrm{t}} \quad=$ non discretionary accrualpada tahun $\mathrm{t}$

$\mathrm{DAC}_{\mathrm{t}} \quad=$ discretionary accrual padatahun $\mathrm{t}$

$\mathrm{TA}_{\mathrm{t}-1} \quad=$ total aktiva pada tahun $\mathrm{t}-1$

$\triangle \mathrm{REV}_{\mathrm{t}} \quad=$ pendapatan perusahaan pada tahun $\mathrm{t}$ dikurangi pendapatan tahun $\mathrm{t}-1$

$\triangle \mathrm{REC}_{\mathrm{t}} \quad=$ piutang perusahaan i pada tahun $\mathrm{t}$ dikurangi piutang tahun $\mathrm{t}-1$

$\mathrm{PPE}_{\mathrm{t}} \quad=$ property, plant, and equipment pada tahun $\mathrm{t}$

$\mathrm{a}_{1}, \mathrm{a}_{2}$, dan $\mathrm{a}_{3}=$ koefisien regresi persamaan regresi OLS

$\varepsilon_{\mathrm{t}} \quad=$ error term tahun $\mathrm{t}$

Untuk menguji hipotesis dilakukan langkah-langkah sebagai berikut:

1. Mengelompokkan semua perusahaan yang mempunyai discretionary accrual yang lebih besar daripada nol.

2. Mengelompokkan hasil data menjadi dua kelompok, yaitu life cycle perusahaan dikelompokkan ke dalam kelompok growth-mature, dan mature-stagnant.

3. Menguji normalitas data dengan One Sample Kolmogorov-Smirnov Test (untuk mengetahui alat analisis yang digunakan, parametrik atau non parametrik).

4. Membandingkan nilai rata-rata masing-masing kelompok perusahaan.

5. Menyimpulkan hasil analisis.

\section{Metode Analisis Data}

Statistik deskriptif dalam penelitian pada dasarnya merupakan proses transformasi data penelitian dalam bentuk tabulasi sehingga mudah dipahami dan diinterprestasikan, (Indriantoro dan Supomo, 2002). Statistik deskriptif hanya berhubungan dengan menguraikan atau memberikan keterangan-keterangan mengenai suatu data keadaan atau fenomena. Uji normalitas bertujuan untuk menguji apakah dalam model regresi,variabel pengganggu atau residual memiliki distribusi normal. Ada dua cara untuk mendeteksi apakah residual berdistribusi normal atau tidak dengan analisis grafis dan uji statistik (Ghozali, 2009). Independent sample t-test adalah jenis uji statistika yang bertujuan untuk membandingkan rata-rata dua grup yang tidak saling berpasangan atau tidak saling berkaitan. Tidak saling berpasangan dapat diartikan bahwa penelitian dilakukan untuk dua subjek sampel yang berbeda.

\section{ANALISIS DAN PEMBAHASAN}

\section{Analisis}

Dari 33 perusahaan manufaktur yang terpilih, kemudian dilakukan pengelompokan perusahaan berdasarkan pada titik kritis siklus hidup perusahaan dengan cara mengelompokan pertemuan antara growth-mature dan mature-stagnant sebagai titik kritis dan kelompok lain sebagai pembanding. Tabel 4.1 menunjukkan bahwa jumlah sampel titik kritis sebanyak 56 dengan masing-masing jumlah titik kritis pada perubahan growth-mature sebanyak 44 dan jumlah titik kritis pada perubahan mature-stagnant sebanyak 12 perusahaan. Sedangkan jumlah sampel pembanding sebanyak 47 dengan masing-masing 
jumlah pembanding pada perubahan growth-mature sebanyak 35 dan jumlah pembanding pada perubahan mature-stagnant sebanyak 12. Hal ini diidentifikasi dengan melihat perubahan siklus hidup perusahaan dari tahap growth ke mature (kelompok growth-mature) dan dari tahap mature ke stagnant (kelompok mature-stagnant).

Tabel 4.1. Statistik Deskriptif

\begin{tabular}{lll}
\hline Titik Kritis & Titik kritis & Pembanding \\
\hline Growth-Mature & 44 & 36 \\
Mature-Stagnant & 12 & 12 \\
\hline Jumlah & $\mathbf{5 6}$ & $\mathbf{4 8}$ \\
\hline
\end{tabular}

Sumber: Data Sekunder BEI tahun 2006-2013

Tabel 4.2 menunjukkan statistik deskriptif untuk perusahaan yang berada pada titik kritis growthmature dan mature-stagnant. Discretionary accrual yang dimasukkan adalah discretionary accrual baik yang positif maupun negatif. Mean discretionary accrual untuk kelompok growth-mature yaitu sebesar 0,003526 lebih besar dibandingkan kelompok mature-stagnant sebesar -0,018854. Sedangkan untuk kelompok pembanding growth-mature yaitu sebesar 0,037389 lebih kecil dibandingkan kelompok pembanding mature-stagnant sebesar 0,040000.

Tabel 4.2. DAC Pada Ttik Kritis

\begin{tabular}{lll}
\hline Mean & Growth-Mature & Mature-Stagnant \\
\hline DAC Titik Kritis &, 003526 &,- 018854 \\
DAC Pembanding &, 037389 &, 040000 \\
\hline Sumber: Perhitungan SPSS & &
\end{tabular}

Hasil uji normalitas pada tabel 4.3 menunjukkan bahwa signifikansi lebih besar daripada 0,05 yaitu sebesar 0,107 dan 0,261 sehingga dapat dikatakan bahwa distribusi data berdistribusi normal. Demikian pula hasil uji normalitas pada tabel 4.4 menunjukkan bahwa signifikansi lebih besar daripada 0,05 yaitu sebesar 0,630 dan 0,504 sehingga dapat dikatakan bahwa distribusi data berdistribusi normal.

Tabel 4.3 Uji Distribusi Normal Growth - Mature One-Sample Kolmogorov-Smirnov Test

\begin{tabular}{|c|c|c|c|}
\hline & & G-M & Pembanding \\
\hline $\mathrm{N}$ & & 88 & 72 \\
\hline & Mean &, 003526 & ,037389 \\
\hline 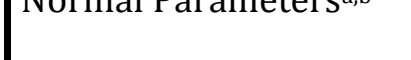 & Std. Deviation & ,0687309 & , 1428348 \\
\hline Fytromo & Absolute & ,129 & 119 \\
\hline 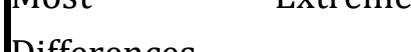 & Positive & ,116 & 119 \\
\hline Dinterences & Negative &,- 129 &,- 093 \\
\hline Kolmogorov-Smirnov Z & & 1,211 & 1,008 \\
\hline Asymp. Sig. (2-tailed) & & 107 & 261 \\
\hline
\end{tabular}

a. Test distribution is Normal.

b. Calculated from data. 
Tabel 4.4 Uji Distribusi Normal Growth - Mature - Stagnant

One-Sample Kolmogorov-Smirnov Test

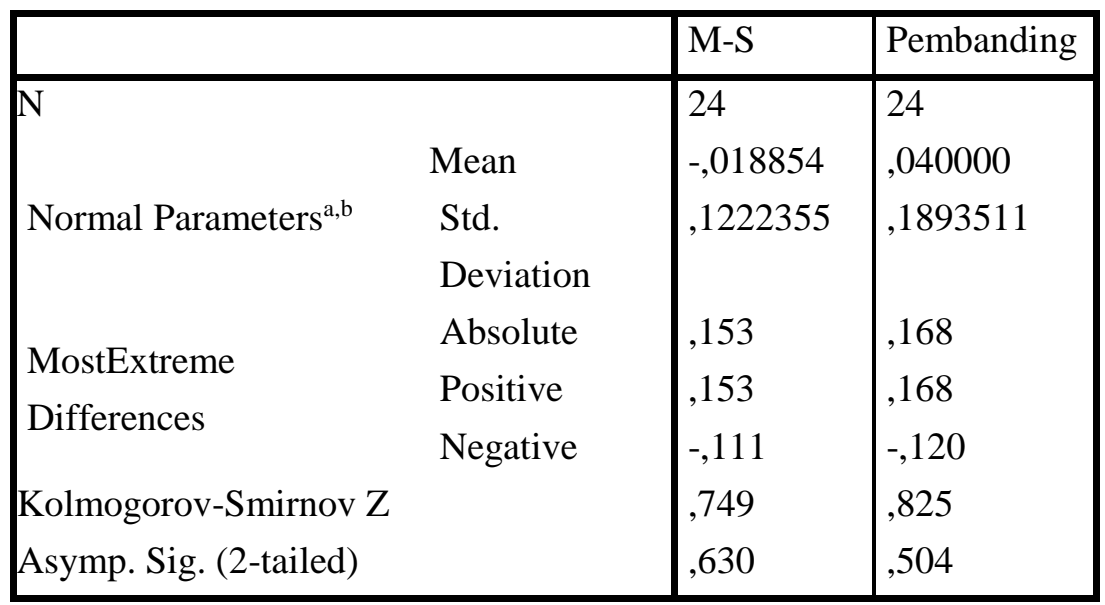

a. Test distribution is Normal.

b. Calculated from data.

\section{Hasil Pengujian Hipotesis}

Hasil Pengujian Tahap Growth-Mature menunjukkan bahwa signifikansi lebih dari 0,05 $(0,051)$ Hal ini menunjukkan bahwa perusahaan yang berada pada titik kritis growth-mature tidak terbukti memiliki discretionary accrual yang berbeda secara signifikan sehingga H1 tidak didukung. Adapun hasil ini menunjukkan bahwa signifikansi lebih dari 0,05 (0,207). Hal ini menunjukkan bahwa perusahaan yang berada pada titik kritis mature-stagnant tidak terbukti memiliki discretionary accrual yang berbeda secara signifikan sehingga $\mathrm{H} 2$ tidak didukung.

\section{Pembahasan}

Tabel 4.6 dan Tabel 4.7 menunjukkan bahwa hipotesis H1 dan H2 tidak didukung. Hal ini menunjukkan bahwa adanya persamaan yang signifikan antara perusahaan yang berada pada titik kritis growth-mature dan mature-stagnant dengan yang tidak berada pada titik kritis perubahan siklus hidup perusahaan.

Tabel 4.5. Hasil IndependentSampels t-Test Mature-Stagnant

Independent Samples Test

\begin{tabular}{|c|c|c|c|c|c|c|c|c|c|c|}
\hline & \multicolumn{2}{|c|}{$\begin{array}{l}\text { Levene's Test } \\
\text { for Equality of } \\
\text { Variances }\end{array}$} & \multicolumn{7}{|c|}{ t-test for Equality of Means } \\
\hline & & \multirow[t]{2}{*}{$F$} & \multirow[t]{2}{*}{ Sig. } & \multirow[t]{2}{*}{$\mathrm{t}$} & \multirow[t]{2}{*}{$\mathrm{df}$} & \multirow{2}{*}{$\begin{array}{l}\text { Sig. } \\
(2- \\
\text { taile } \\
\text { d) }\end{array}$} & \multirow[t]{2}{*}{$\begin{array}{l}\text { Mean } \\
\text { Difference }\end{array}$} & \multirow[t]{2}{*}{$\begin{array}{l}\text { Std. Error } \\
\text { Difference }\end{array}$} & $\begin{array}{l}95 \% \\
\text { Interval } \\
\text { Difference }\end{array}$ & $\begin{array}{l}\text { Confidence } \\
\text { of the }\end{array}$ \\
\hline & & & & & & & & & Lower & Upper \\
\hline DAC & $\begin{array}{l}\text { Equal } \\
\text { variances } \\
\text { assumed } \\
\text { Equal } \\
\text { variances } \\
\text { not assumed }\end{array}$ & 1,667 & ,203 & $\begin{array}{l}-1,279 \\
-1,279\end{array}$ & 39,333 & $\begin{array}{l}\text {,207 } \\
\text { 208 }\end{array}$ &,- 0588542 & ,0460051 &,- 1518831 & $\begin{array}{l}\text {,0337494 } \\
0341748\end{array}$ \\
\hline
\end{tabular}

Sumber: Perhitungan SPSS 
Hasil penelitian ini konsisten dengan penelitian yang dilakukan oleh Hastuti (2010), menunjukkan bahwa mean discretionary accrual perusahaan kecil paling tinggi dilakukan pada perusahaan yang berada pada tahap mature dan paling rendah dilakukan pada perusahaan yang berada pada tahap growth. Sedangkan mean discretionary accrual perusahaan berukuran medium semakin rendah seiring dengan perubahan life cycle perusahaan dari tahap growth, mature, dan stagnant. Kemudian, mean discretionary accrual perusahaan berukuran kecil paling tinggi dilakukan pada perusahaan yang berada pada tahap mature dan paling rendah dilakukan pada perusahaan yang berada pada tahap growth. Namun, berdasarkan hasil uji ANOVA, perbedaan mean discretionary accrual di antara variabel ukuran dan life cycle perusahaan menunjukkan tidak ada perbedaan di ketiga kelompok untuk masing-masing variabel.

Pengaruh tidak didukungnya hipotesis penelitian dikarenakan ada kemungkinan ditemukannya bukti perusahan yang melakukan perubahan manajemen laba dengan pola yang teratur. Perusahaan memerlukan manajemen laba yang mampu memakmurkan perusahaannya sehingga perusahaan melakukan manajemen laba. Dalam pelaksanaannya, manajemen laba yang dilakukan harus memiliki pola yang teratur dalam artian kelebihan laba tahun ini dapat menutup kekurangan laba tahun berikutnya begitu pula sebaliknya. Sesuai dengan penelitian Myers dan Skinner dalam Dechow dan Skinner (2000), yang menyatakan bahwa sulit memisahkan earnings management dari suatu kebijakan akuntansi yang sah pada suatu perusahaan.

\section{E. SIMPULAN DAN SARAN}

\section{Simpulan}

Penelitian ini bertujuan untuk menguji apakah perusahaan yang berada pada titik kritis growthmature dan mature-stagnant memiliki perbedaan yang signifikan dengan perusahaan yang tidak berada pada titik kritis perubahan siklus hidup perusahaan. Hasil dari penelitian ini menunjukkan bahwa perusahaan-perusahaan yang berada pada titik kritis growth-mature dan mature-stagnant tidak terbukti memiliki perbedaan yang signifikan dengan perusahaan yang tidak berada pada titik kritis perubahan siklus hidup perusahaan.

Dapat disimpulkan bahwa tidak adanya bukti perbedaan manajemen laba yang terdapat dalam perusahaan-perusahaan manufaktur yang terdaftar di Bursa Efek Indonesia. Bagi investor sebagai pihak yang terkait langsung dengan laporan keuangan, bukti penelitian ini diharapkan dapat membantu investor dalam menganalisis adanya manajemen laba yang dikaitkan dengan manajemen laba menaikkan laba atau menurunkan laba berdasarkan pada perubahan life cycle perusahaan.

Penelitian ini memilki beberapa keterbatasan. Beberapa keterbatasan pada penelitian ini adalah sebagai berikut:

1. Perusahaan yang diambil sebagai sampel hanya dari kelompok perusahaan manufaktur sehingga belum tentu dapat digeneralisasi untuk perusahaan non manufaktur.

2. Penelitian ini menggunakan model life cycle yang digunakan Anthony dan Ramesh (1992) dengan membagi life cycle perusahaan ke dalam tiga tahap (growth, mature dan stagnant) sehingga ada kemungkinan terdapat perbedaan hasil jika digunakan dengan model lain yang membagi life cycle perusahaan ke dalam empat tahap atau lima tahap. 


\section{Saran}

Penelitian ini diharapkan dapat memberikan ide untuk pengembangan penelitian selanjutnya. Berdasarkan keterbatasan yang ada, penelitian selanjutnya dapat mempertimbangkan hal-hal berikut ini:

1. Perlu dilakukan pengujian terhadap perusahaan non manufaktur sehingga penelitian ini lebih dapat digeneralisasi.

2. Perlu dilakukan pengujian dengan menggunakan model life cycle yang lain.

\section{REFERENSI}

Anthony, Joseph H. dan K. Ramesh. 1992. Association between Accounting Performance Measures and Stock Prices: A Test of the Life Cycle Hypothesis. Journal of Accounting and Economics 15, 203 227.

Astika, Ida B. P. 2012. Manajemen Laba Dan Motif Yang Melandasinya. Jurnal Ilmiah Akuntansi dan Bisnis, Universitas Udayana, Denpasar.

Atmini, Sari. 2002. Asosiasi Siklus Hidup Perusahaan dengan Incremental Value-Relevance Informasi Laba dan Arus Kas. Jurnal Riset Akuntansi Indonesia, 5 (3), 257-276.

Beasley, M. S. 1996. An Empirical Analysis of The Relation Between The Board of Director Composition and Financial Statement Fraud. The Accounting Review ,71 (4), 443-465.

Black, Ervin L. 1998. Which is More Value Relevant: Earnings or Cash Flows? A Life Cycle Examination. Working Paper, University of Arkansas, Fayetteville, Arkansas.

Chan, K., L.K. Chan, N. Jegadeesh, dan J. Lakonishok. 2001. Earnings Quality and Stock Returns. NBER Working Paper Series.

Dechow, Patricia M., Richard G. Sloan, dan Amy P. Sweeney. 1995. Detecting Earnings Management. The Accounting Review, 70 (2), 193-225.

Dechow, Patricia M. dan Douglas J. Skinner. 2000. Earnings Management: Reconciling the Views of Accounting Academics, Practitioners, and Regulators. Accounting Horizons, 14 (2), 235-250.

Degeorge, François, Jayendu Patel, dan Richard Zeckhauser. 1999. Earnings Management to Exceed Thresholds. Journal of Business, 72 (1), 1-33.

Ghozali, Imam. 2005. Aplikasi Analisis Multivariate dengan Program SPSS. Semarang: Badan Penerbit Undip.

Hamid, Abd. 1999. Studi terhadap Strategi Prospektor dan Defender dan Hubungannya dengan Harga Saham: Analisis dengan Pendekatan Life Cycle Theory. Tesis, Universitas Gadjah Mada, Yogyakarta.

Harrison, P. D.; A., Harrell. 1993. "Impac of Adverse Selection on Managers Project Evaluation Decisions". Academy of Management Journal, Vol. 36, No. 3, 635-643.

Hastuti, Sri. 2006. The Influence of Companies' Life Cycles on Earnings Management Behavior. The Indonesian Journal of Accounting Research, 13 (2), 117-132.

Hastuti, Sri. 2010. Studi tentang Pemilihan Kebijakan Akuntansi dan Hubungannya dengan Manajemen Laba: Analisis dengan Pendekatan Siklus Hidup Perusahaan dan Ukuran Perusahaan. Paper dipresentasikan pada acara Seminar Nasional Hasil Penelitian Dosen Kopertis Wilayah V, Yogyakarta. 
Hastuti, Sri. 2011. Titik Kritis Manajemen Laba pada Perubahan Tahap Life Cycle Perusahaan: Analisis Manajemen Laba Riil Dan Manajemen Laba Akrual. Jurnal Akuntansi dan Keuangan Indonesia, Vol. 8, No. 2, Desember: 107-122.

Hayn, Carla. 1995. The Information Content of Losses. Journal of Accounting and Economics, 20 (2), 125-153.

Hughes, J. S. 1982. “Agency and Stochastic Dominance”. Journal of Financial and Quantitative Analysis, Vol. XVII, No. 3.

Indriantoro, Nur dan Supomo, Bambang. 2009. Metodologi Penelitian Bisnis untuk Akuntansi \& Manajemen. Yogyakarta: BPFE.

Jensen, M.C. dan W.H. Meckling. 1976. "Theory of the Firm: Managerial Behavior, Agency Cost and Ownership Structure”. Journal of Financial Economics, Vol. 3, No. 4.

Jones, J. 1991. Earnings Management during Import Relief Investigations. Journal of Accounting Research, 29 (2), 193-228.

Kotler, Philip. 1997. Marketing Management: Analysis, Planning, Implementation, and Control. New Jersey: International Edition (Ninth Edition), Prentice Hall International, Inc.

Myers, L.A. dan D. J. Skinner. 2000. Earnings Momentum and Earnings Management. Working Paper, University of Michigan.

Palupi, Margaretta Jati. 2004. Pengaruh Siklus Hidup Perusahaan terhadap Koefisien Respon Laba: Bukti Empiris pada Bursa Efek Jakarta. Tesis, Universitas Gadjah Mada, Yogyakarta.

Peasnell, K.V., P.F. Pope dan S. Young. 2005. Board Monitoring and Earnings Management: Do Outside Directors Influence Abnormal Accruals? Journal of Business Finance \& Accounting, 32 (7) \& (8), 1311-1346.

Pratisto, A. 2004. Cara Mudah Mengatasi Masalah Statistik dan Rancangan Percobaan dengan SPSS 17. Jakarta: Bumi Aksara.

Pratiwi, Lusy Indah. 2013. Analisis Manajemen Laba pada Saat Perubahan Tahap Siklus Hidup di Perusahaan Manufaktur yang Terdaftar Di Bei. Skripsi, Universitas Katolik Widya Mandala, Surabaya.

Quinn, Robert E. dan Kim Cameron. 1983. Organizational Life Cycles and Shifting Criteria of Effectiveness: Some Preliminary Evidence. Management Science, 29 (1), 33-51.

Ring, D. R. dan J. E. Swan. 1979. Product Life-Cycle Research: A Literature Review. Journal of Business Research, 7 (3), 219-242.

Ross, A. S. 1973. "The Economic Theory of Agency: The Principal's Problem”. American Economic Association, Volume. 63, No.2.

Santoso, Singgih. 2001. SPSS Versi 10, Mengolah Data Statistik secara Profesional. Jakarta: Penerbit PT. Elex Media Komputindo, Kelompok Gramedia.

Schori, Thomas R. dan Michael L. Garee. 1998. Like Products, Companies have Life Cycle. Marketing Views, 32 (13), 4.

Scott, William R. 2003. Financial Accounting Theory. Canada: Prentice-Hall.

Sloan, Richard G. 1996. Do Stock Prices Fully Reflect Information in Accruals and Cash Flow About Future Earnings? The Accounting Review, 71 (3), 289-315.

Shank, J. K. dan V. Govindarajan. 1993. Strategic Cost Management: The New Tool for Competitive Advantage. The Free Press. 
Sugiyono, 2009. Metode Penelitian Kuantitatif, Kualitatif dan R \& D.Bandung: Alfabeta.

Sulistiawan, Dedhy, Januarsi, Yeni, dan Alvia, Lisa. 2011. Creative Accounting, Mengungkap Manajemen Laba dan Akuntansi. Jakarta: Salemba Empat.

Teoh, Siew Hong, Ivo Welch, dan T.J. Wong. 1998. Earnings Management and The Underperformance of Seasoned Equity Offerings. Journal of Financial Economics, 50 (1), 63-99.

The President Post. 2013. Dampak Kenaikan BBM Bagi Dunia Usaha. Diambil dari: http://thepresidentpostindonesia.com/2013/06/24/dampak-kenaikan-bbm-bagi-dunia-usaha/, tanggal 6 Oktober 2015 